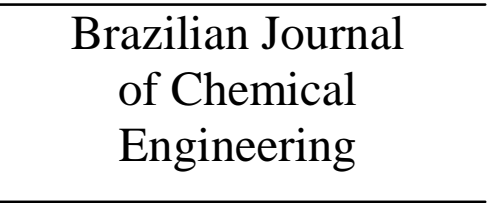

ISSN 0104-6632

Printed in Brazil www.abeq.org.br/bjche

Vol. 26, No. 01, pp. 89 - 98, January - March, 2009

\title{
CONTROL OF INTEGRATING PROCESS WITH DEAD TIME USING AUTO-TUNING APPROACH
}

\author{
G. Saravanakumar ${ }^{*}$ and R. S. D. Wahidabanu ${ }^{2}$ \\ ${ }^{1}$ Department of Instrumentation and Control, Manipal Institute of Technology, \\ Manipal-576104, Karnataka, India. \\ E-mail: saravanakumar579@yahoo.com \\ ${ }^{2}$ Department of Electronics and Communication Engineering, \\ Govt. College of Engineering, Salem, Tamilnadu, India. \\ E-mail: rsdwb@yahoo.com
}

(Submitted: April 26, 2007 ; Revised: February 1, 2008 ; Accepted: February 23, 2008)

\begin{abstract}
A modification of Smith predictor for controlling higher order processes with integral action and long dead-time is proposed in this paper. The controller used in this Smith predictor is an IntegralProportional Derivative controller, where the Integrator is in the forward path and the Proportional and Derivative control are in the feedback, acting on the feedback signal. The main objective of this paper is to design a dead time compensator, which has minimum tuning parameters, simple controller tuning, and robust performance of tuning formulae, and to obtain a critically damped system that is as fast as possible in its set point and load disturbance rejection performance. The controller in this paper is tuned by an adaptive method. This paper also presents a survey of various dead time compensators and their performance analysis.

Keywords: Dead time compensator; Controller; Auto tuning; Integrating process.
\end{abstract}

\section{INTRODUCTION}

Smith predictors are effective tools for compensating the dead-time associated with the processes. During the last 20 years, numerous extensions and modifications of the Smith predictors, also called dead-time compensators, DTC, (Saravanakumar et al., 2006) have been proposed. The design of the dead time compensators (Hagglund, 1992) requires the tuning of more parameters (primary controller and model parameters) than classical PID controllers. This has been a drawback for the application of DTC in industry, which required 5 parameters. To simplify the tuning of the DTC controller proposed by Smith, a four parameter controller was proposed (Coughanowr, 1991).

\section{NON-SELF REGULATING PROCESSES}

\section{DTC by Watanabe and Ito (1981)}

To overcome the drawback of the DTC discussed previously, Watanabe and Ito (1981) proposed the dead time compensator presented in Figure 1.

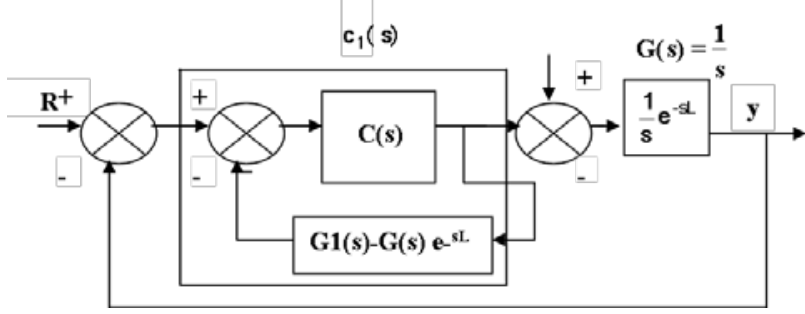

Figure 1: DTC proposed by Watanabe and Ito (1981)

*To whom correspondence should be addressed 
Simulation studies have shown that, with a PI controller the set point and load disturbances were either very oscillatory or highly damped when the process had a large dead-time. The response of the system also tends to be slow. Much better performance was obtained when the main controller was of the PID type.

$$
\frac{\mathrm{Y}(\mathrm{s})}{\mathrm{u}(\mathrm{s})}=\mathrm{G}(\mathrm{s}) \mathrm{e}^{-\mathrm{sL}}
$$

$\mathrm{G}(\mathrm{s})=\frac{1}{\mathrm{~s}}$

$$
\mathrm{G}_{1}(\mathrm{~s})=\frac{\mathrm{G}(\mathrm{s})}{1+\mathrm{sL}}
$$

Here $G(s)$ is the plant and $G_{1}(s)$ is the model. This was the assumption made in this DTC. Here the drawback is that the set point response is rather slow. It too had three controller parameters to be determined, $\mathrm{K}_{\mathrm{c}}, \mathrm{T}_{\mathrm{i}}$ and $\mathrm{T}_{\mathrm{d}}$.

\section{DTC by Astrom et al. (1994)}

To overcome the drawback of the Watanabe method, Astrom et al. (1994) proposed a DTC for the integrating process that was considerably faster in set point response and had a better load disturbance rejection. A convenient property of the controller was that it decouples the set point response from the load response. However, the number of tuning parameters, if the velocity gain is unknown, equals six.

\section{DTC by Matausek and Micic (1996)}

The controller proposed by Matausek and Micic (1996), presented in Figure 2, is a simple and straightforward modification of the Smith predictor for the integrating process. The high closed loop system performances, i.e., fast set point response and satisfactory load disturbance rejection, can be obtained even in the presence of the unmodelled dynamics. There are only three adjustable parameters that have a clear physical interpretation and can easily be tuned manually.

$$
\begin{aligned}
& \mathrm{Ko}=\frac{1}{2 \mathrm{Kp} \tau} \\
& \mathrm{K}_{\mathrm{r}}=\frac{1}{\mathrm{~K}_{\mathrm{p}} \mathrm{T}_{\mathrm{r}}}
\end{aligned}
$$

The drawback is that it cannot perform better for load response for processes with longer dead-times.

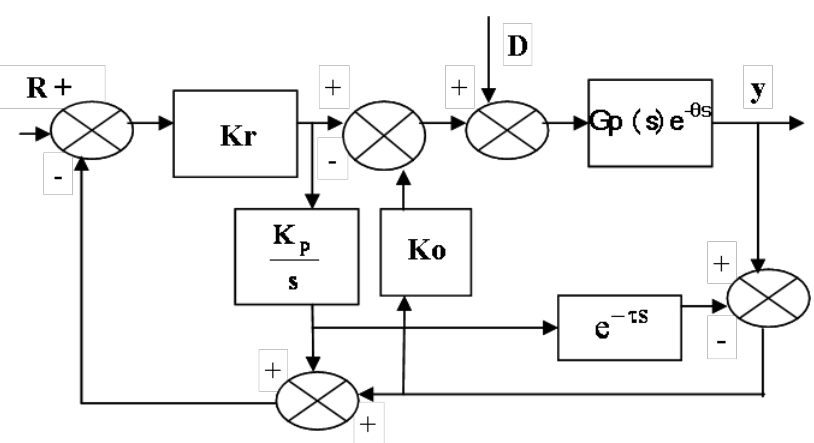

Figure 2: Modified DTC proposed by Matausek and Micic (1996).

\section{DTC by Normey-Rico and Camacho (1999)}

This structure, presented in Figure 3, was the modification of the Watanabe structure for the integrating process by including the filter. The tuning criterion was based on the definition of the closed loop performances and considers that the model of the process is not precisely known. Using the estimation of the dead-time and the velocity gain of the plant, the proposed control law has three parameters (To, Kg, L) that can be tuned manually like a PID Controller. This method, Normey-Rico and Camacho (1999) was better in both set point and load disturbance performance when compared with Matusek and Micic's method for longer dead-times. The method presented is applicable to PID Control algorithms in both the Interacting and noninteracting derivative forms.

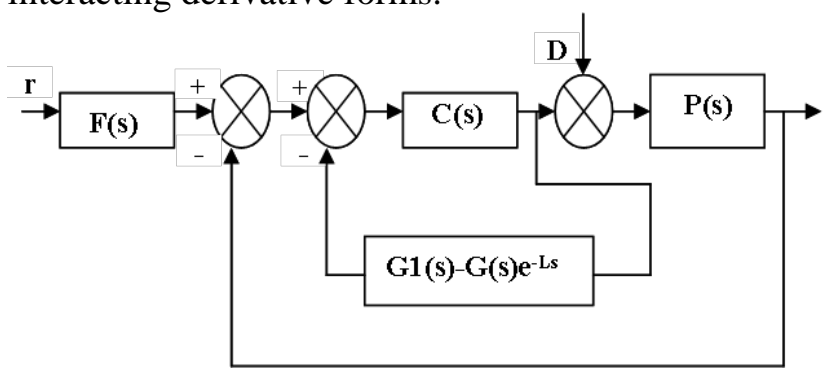

Figure 3: DTC proposed by Normey-Rico and Camacho (1999).

\section{DTC by Rice and Cooper (2002)}

Here the work was based on the IMC structure, to derive tuning correlations for integrating processes. One novel contribution of this work (Rice and Cooper, 2002) was the extension of tuning 
correlations to include the PID with derivative filter forms. This work is applicable where a compromise is sought between settling time and overshoot, while minimizing the "chatter" in the controller output due to noise. This method also requires five parameters to be determined, two model parameters and three controller parameters.

\section{DTC by Wang et al. (2006)}

The scheme of this controller is presented in Figure 4. Here the region of the control parameters to guarantee the system stability was characterized. The control parameters to achieve the given gain and phase margins were determined. Furthermore, the constraint on achievable GPM was derived. These results were obtained on the basis of the normalized system that involves only two free parameters and one filter parameter for a total of three parameters. Here (Wang et al., 2006) the set point response was fast and the load response was rather slow for the integrating process.

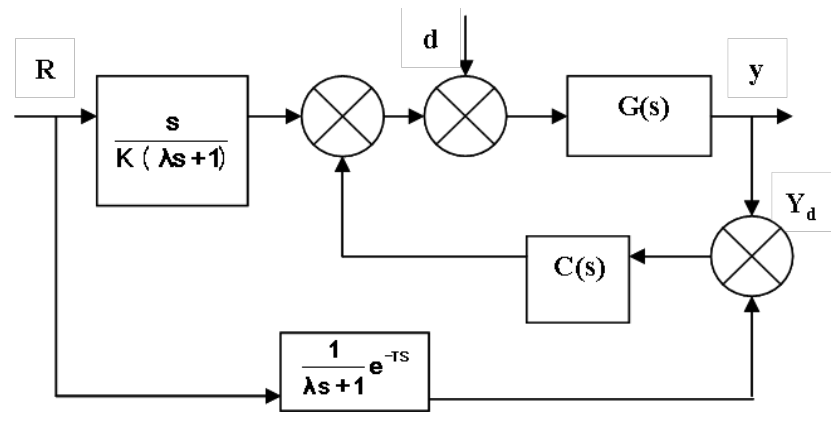

Figure 4: DTC proposed by Wang et al. (2006).

So in all the DTCs discussed above, it was possible to achieve a perfect response, either with set point or load response. Hence it is necessary to design a method that will be able to achieve a critically damped system and is as fast as possible in both set point and load disturbance.

\section{PERFORMANCE ANALYSIS OF MODIFIED DTC FOR NON-REGULATING PROCESSES}

\section{Non-Self Regulating Processes}

It is not uncommon for some temperature, level, pressure and other measured process variables to move in an unbounded manner when perturbed in open loop by a manipulated or disturbance variable. Such behaviour is characteristic of non-self regulating processes. If the DTC's used for the selfregulating processes are applied for the non-selfregulating processes, these predictors exhibit a steady-state error in their load response. Consequently, there is a need for the modified design of DTC's to give satisfactory response for the integrating processes.

Several new Smith predictors proposed by various authors were considered and their responses were analyzed. In Watanabe's method (Watanabe and Ito, 1981), the response for the set point and load disturbance rejection were better for the PID controller than the PI controller. The set point response was rather slow. In Matusek and Micic's method, a new DTC method was proposed, which had a very good set point and load response compared with the previous ones, but the drawback was it cannot produce a better result with a longer dead time. In Rice and Cooper's method, an IMC based DTC was proposed particularly to reject the chatter in the controller for integrating processes. When affected by noise disturbances, the results proved that this method was better than the tuning formulas proposed by Ziegler-Nichols (1942) (ZN) and Tyreus and Luyben (1992). Wang et al. (2006) proposed a modified DTC with two degrees of freedom, a filter and a controller. This method gave a good set point response and satisfactory load response. In all the above methods, none of the modified DTC's gave a satisfactory performance for both set point and load disturbance. A compromise is obtained between the set point and load disturbance response with the proposed method in this paper.

\section{Proposed Alternate Method}

The proposed method is presented in Figure 5.

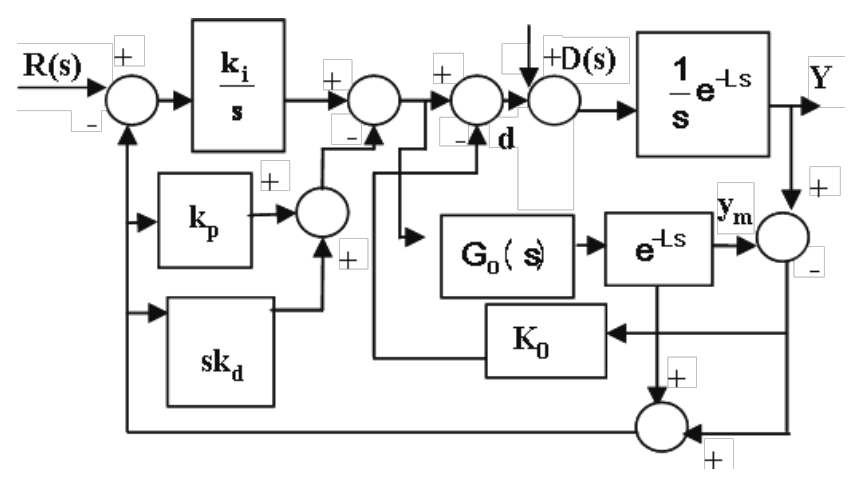

Figure 5: Modified Smith predictor approach. 
Consider the plant with transfer function $\mathrm{G}_{\mathrm{p}}(\mathrm{s})=\frac{1}{\mathrm{~s}} \mathrm{e}^{-\mathrm{Ls}}$, where $\mathrm{e}^{-\mathrm{Ls}}$ represents the time delay of L seconds. Assume that the time delay $\mathrm{L}$ is known and the process is $\frac{1}{\mathrm{~s}}$. Here $\mathrm{G}_{0}(\mathrm{~s})=\frac{\mathrm{G}_{\mathrm{p}}(\mathrm{s})}{1+\mathrm{sL}}$ (Coughanowr, 1991) and L(process) $=\mathrm{L}$ (model) The modification (Saravanakumar et al., 2006) consists of the additional feedback path $\left(K_{0} \neq 0\right)$, from the difference of the plant output $\mathrm{Y}$ and the model output $\mathrm{Y}_{\mathrm{m}}$ to the control input $\mathrm{u}$. When $\mathrm{K}_{0}=0$, the Smith predictor is used. When $\mathrm{K}_{0} \neq 0$, then the modified Smith predictor is obtained. The controller used in this Smith predictor is an I-PD controller where the Integrator is in the forward path and the proportional and derivative control are in the feedback acting on the feedback signal. The controller is tuned by both the Ziegler-Nichols (ZN) method and the relay method. Since the relay method gives the immediate value of ultimate gain and ultimate period, it is preferable to the $\mathrm{ZN}$ method.

The set point and the load disturbance response is given by

$\mathrm{Y}(\mathrm{s})=\mathrm{H}_{\mathrm{r}}(\mathrm{s}) \mathrm{R}(\mathrm{s})+\mathrm{H}_{\mathrm{d}}(\mathrm{s}) \mathrm{D}(\mathrm{s})$

where

$$
\begin{gathered}
\mathrm{H}_{\mathrm{r}}(\mathrm{s})=\frac{\frac{\mathrm{G}_{\mathrm{p}}(\mathrm{s}) \mathrm{G}_{\mathrm{i}}(\mathrm{s})}{1+\left(1-\mathrm{e}^{-\mathrm{Ls}}\right)\left(\mathrm{G}_{\mathrm{i}}(\mathrm{s}) \mathrm{G}_{\mathrm{pd}}(\mathrm{s})\right) \mathrm{G}_{0}(\mathrm{~s})}}{1+\frac{\mathrm{G}_{\mathrm{i}}(\mathrm{s})+\mathrm{G}_{\mathrm{pd}}(\mathrm{s})}{1+\left(1-\mathrm{e}^{-\mathrm{Ls}}\right)\left(\mathrm{G}_{\mathrm{i}}(\mathrm{s})+\mathrm{G}_{\mathrm{pd}}(\mathrm{s})\right) \mathrm{G}_{\mathrm{o}}(\mathrm{s})}} \\
\mathrm{H}_{\mathrm{d}}(\mathrm{s})=\frac{\frac{\mathrm{G}_{\mathrm{p}}(\mathrm{s})}{1+\mathrm{G}_{\mathrm{p}}(\mathrm{s}) \mathrm{K}_{\mathrm{o}}}}{1+\frac{\mathrm{G}_{\mathrm{i}}(\mathrm{s}) \mathrm{G}_{\mathrm{pd}}(\mathrm{s})}{1+\left(1-\mathrm{e}^{-\mathrm{Ls}}\right)\left(\mathrm{G}_{\mathrm{i}}(\mathrm{s})+\mathrm{G}_{\mathrm{pd}}(\mathrm{s})\right) \mathrm{G}_{\mathrm{o}}(\mathrm{s})} \mathrm{G}_{\mathrm{p}}(\mathrm{s})}
\end{gathered}
$$

where,

$$
\mathrm{G}_{\mathrm{i}}(\mathrm{s})=\frac{\mathrm{K}_{\mathrm{i}}}{\mathrm{s}}, \quad \mathrm{G}_{\mathrm{pd}}(\mathrm{s})=\mathrm{K}_{\mathrm{p}}+\mathrm{sK}_{\mathrm{d}} \quad \text { and } \quad \mathrm{G}_{0}(\mathrm{~s})
$$

represents the estimated transfer function of the plant. From (7) and (8) we have

$$
H_{r}(s)=\frac{G_{0}(s) G_{i}(s) e^{-L s}}{1+\left(G_{i}(s)+G_{p d}(s)\right) G_{0}(s)}
$$

$$
\begin{aligned}
& \mathrm{H}_{\mathrm{d}}(\mathrm{s})=\frac{\mathrm{G}_{\mathrm{p}}(\mathrm{s})}{1+\mathrm{G}_{\mathrm{p}}(\mathrm{s}) \mathrm{K}_{\mathrm{o}}} \\
& \frac{1+\left(1-\mathrm{e}^{-\mathrm{Ls}}\right)\left(\mathrm{G}_{\mathrm{i}}(\mathrm{s})+\mathrm{G}_{\mathrm{pd}}(\mathrm{s})\right) \mathrm{G}_{\mathrm{o}}(\mathrm{s})}{1+\left(\mathrm{G}_{\mathrm{i}}(\mathrm{s})+\mathrm{G}_{\mathrm{pd}}(\mathrm{s})\right) \mathrm{G}_{\mathrm{o}}(\mathrm{s})}
\end{aligned}
$$

for the perfect model of the plant and perfect dead time of the process. If the closed loop system is stable, the set point and the disturbance response for step inputs are as follows:

$$
\begin{aligned}
& \lim _{s \rightarrow 0}\left(H_{r}(s) \frac{1}{s}\right)=\lim _{s \rightarrow 0} H_{r}(s)=1 \\
& \operatorname{lims}_{s \rightarrow 0}\left(H_{d}(s) \frac{1}{s}\right)=\lim _{s \rightarrow 0} H_{d}(s)=0
\end{aligned}
$$

for $\mathrm{K}_{0} \neq 0$.

This shows that there will be no steady-state error for a constant load disturbance.

$G_{0}(s)=\frac{1 e^{-3 s}}{s(1+3 s)}, \quad L=3$

The responses for the set point and load disturbances are shown in the simulation results.

\section{Validation of the Time Constant and Dead Time Relationship}

In this paper it is assumed that the model of the process is $\mathrm{G}_{0}(\mathrm{~s})=\frac{\mathrm{G}_{\mathrm{p}}(\mathrm{s})}{1+\mathrm{sL}}$ and $\mathrm{L}$ (process) $=\mathrm{L}$ (model). That is, the process dead time is equal to the time constant of the model. A method is required to validate this assumption.

Thus, simulation studies were undertaken to validate this assumption. In this paper, the time constant was assumed to be $3 \mathrm{sec}$ as that of the deadtime. Simulation studies are carried out for time constants varying from 0.75 to 6 seconds and various responses are obtained in time domain specifications such as overshoot, rise time, peak time, delay time and settling time, etc.

From the detailed study of these specifications, it is validated that the time constant of the model should be equal to the dead-time of the process. For other time constants a small steady state error is obtained for constant load disturbance. Table 1 shows the various time constant and dead-time 
relationships with values of rise time, peak time, delay time and settling time. In these simulations:

1) Dead-time is considered to be constant for all the simulation study.

2) The time constant is varied from one fourth of the dead-time to double the dead time.

3) Rise time is the time taken by the process to reach $90 \%$ of the final value. Here the observation shows that the rise is slow in the initial stages, then fast with time constant of $3 \mathrm{sec}$ and again slowing down at double the time constant.
(4) Peak magnitude represents the overshoot of the process and is high at the initial and final values of time constant, but low when the time constant matches the dead time.

(5) Settling time is the time taken by the process to settle with its set point value, which is also fast when the time constant matches the dead time, and is slow in all other cases.

So these studies show that when time constant matches the dead time, it is possible to achieve a critically damped system.

Table 1: Validation through time domain specifications

\begin{tabular}{|c|c|c|c|c|c|c|}
\hline $\begin{array}{l}\text { Dead } \\
\text { Time }\end{array}$ & $\begin{array}{c}\text { Time } \\
\text { constant }\end{array}$ & $\begin{array}{c}\text { Rise Time A } \\
\text { (sec) }\end{array}$ & $\begin{array}{c}\text { Peak overshoot } \\
\text { magnitude A }\end{array}$ & $\begin{array}{c}\text { Settling time A } \\
\text { (sec) }\end{array}$ & \begin{tabular}{|c|} 
Peak undershoot \\
Magnitude B
\end{tabular} & $\begin{array}{c}\text { Settling Time } \\
\text { B(sec) }\end{array}$ \\
\hline \multirow{8}{*}{$3 \mathrm{sec}$} & 0.75 & 16 & 1.1 & 60 & \begin{tabular}{|c|}
0.5 \\
\end{tabular} & 150 \\
\hline & 1.5 & 15.5 & 1.09 & 58 & 0.45 & 148 \\
\hline & 2.25 & 15 & 1.08 & 55 & 0.4 & 145 \\
\hline & 3 & 14 & 1.05 & 45 & 0.3 & 140 \\
\hline & 3.75 & 14 & 1.05 & 58 & 0.44 & 145 \\
\hline & 4.5 & 15 & 1.055 & 65 & 0.47 & 150 \\
\hline & 5.25 & 15 & 1.06 & 70 & 0.52 & 155 \\
\hline & 6 & 16 & 1.07 & 80 & 0.55 & 190 \\
\hline
\end{tabular}

A- Represents the time domain specifications of the set point response.

B-Represents the time domain specifications of the load response.

\section{Simulation Results for Validation of Time Constant and Dead Time Relationship}

In Figure 6 for a dead time of 3 sec and time constant of $3 \mathrm{sec}$, the error is of only one polarity (i.e., it never oscillates about the set point). Here the measure of quality is the duration (starting point of disturbance to return of the process variable) of the excursion, for a load change and a maximum error for transient change.

The duration is the time for exceeding the allowable error and to regain the allowable error. The overshoot magnitude is 1.1 and, for the transient change, the process returns to set point at $60 \mathrm{sec}$. For a load change of 1 unit at $100 \mathrm{sec}$, the process

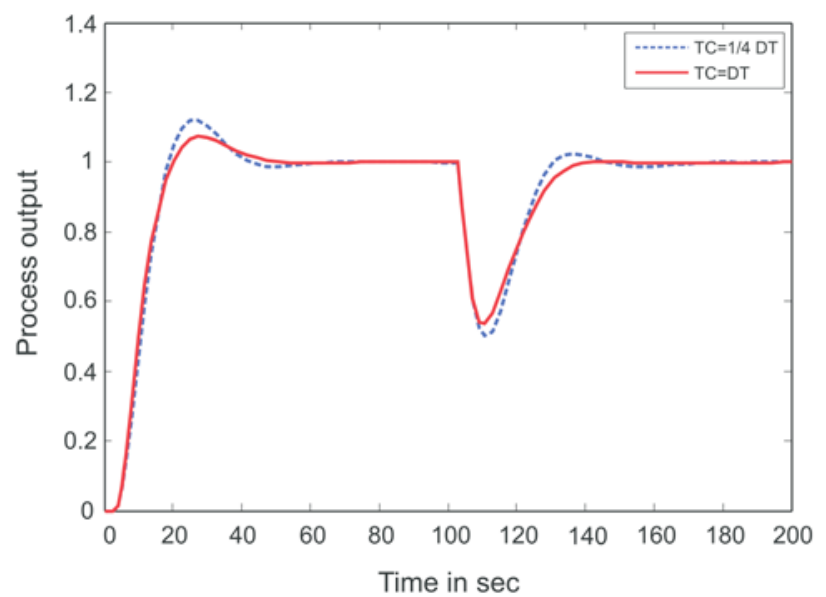

Figure 6: Time constant $=1 / 4$ of Dead time variable returns at $150 \mathrm{sec}$.

In Figure 7 the settling time for the set point response is $58 \mathrm{sec}$, and settling time for the load response is $148 \mathrm{sec}$, which is comparatively higher than the 45 and 140 sec of the time constant=dead time case.

In Figure 8, when the time constant is $3 / 4$ of the dead time, the settling time of the set point response and the load response are $55 \mathrm{sec}$ and $145 \mathrm{sec}$ respectively.

In Figure 9 for a dead time of $3 \mathrm{sec}$ and a time constant of 6 sec (double the dead time), the settling time for transient change is about 80 sec. For a load change of 1 unit at 100sec, the settling time is around 190 sec.

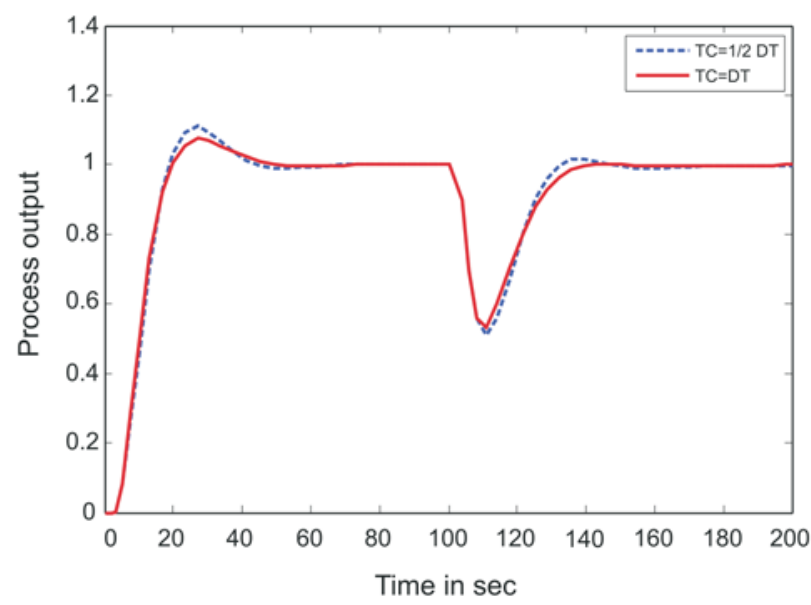

Figure 7: Time constant $=1 / 2$ of Dead time 


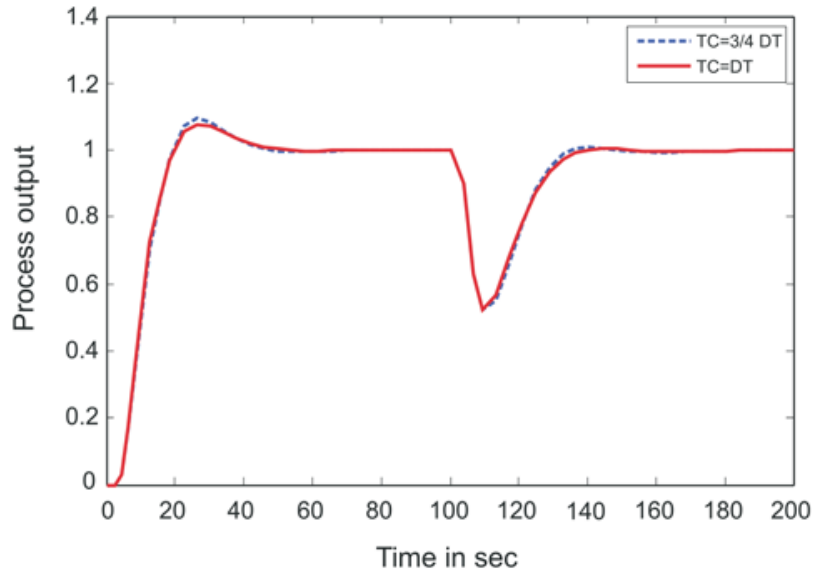

Figure 8: Time constant $=3 / 4$ of Dead time

\section{Adaptive Controller Gains by Auto-Tuning}

This modified Smith predictor (Figure 5) with IPD controller, designed for integrator process with long dead time, can be used for auto-tuning the controller gains whenever the plant parameters changes due to uncertainties. There are many autotuning concepts, which were formulated earlier (Santacesaria and Scattolini, 1993). The auto-tuning concept in this paper first determines the FFT of the plant input for 64 samples and then the FFT of the plant output for 64 samples. Now, the output divided by input of the plant gives the actual frequency response of the plant. Then the frequency response of the model is obtained by giving an impulse input to the model. This model is derived by considering the plant output, plant input and the plant disturbance. Once the least square algorithm is implemented in MATLAB, then the theta values (see equation 22) give the adaptive controller gains, which are the auto-tuned values of the I-PD controller. Now, the determination of I-PD controller gains for auto-tuning in the frequency domain (Saravanakumar et al., 2006) is summarized as follows. Let $G_{p}(s)=\frac{1}{s} e^{-L s}$. The frequency response of this system is $G_{p}(j w)=\frac{1}{j w} e^{-j w L}$. Let $G_{m}(j \omega)$ denote a desired open-loop frequency response of the reference. Then the I-PD controller gains are determined so as to minimize the cost function $\mathrm{J}$, which is defined by the square error between the open loop frequency response of the reference model and that of the actual system as

$\mathrm{J}=\sum_{\mathrm{k}=1}^{\mathrm{M}}\left|\varepsilon\left(\mathrm{j} \omega_{\mathrm{k}}\right)\right|^{2}+\sum_{\mathrm{k}=1}^{\mathrm{M}}\left|\varepsilon\left(-\mathrm{j} \omega_{\mathrm{k}}\right)\right|^{2}$

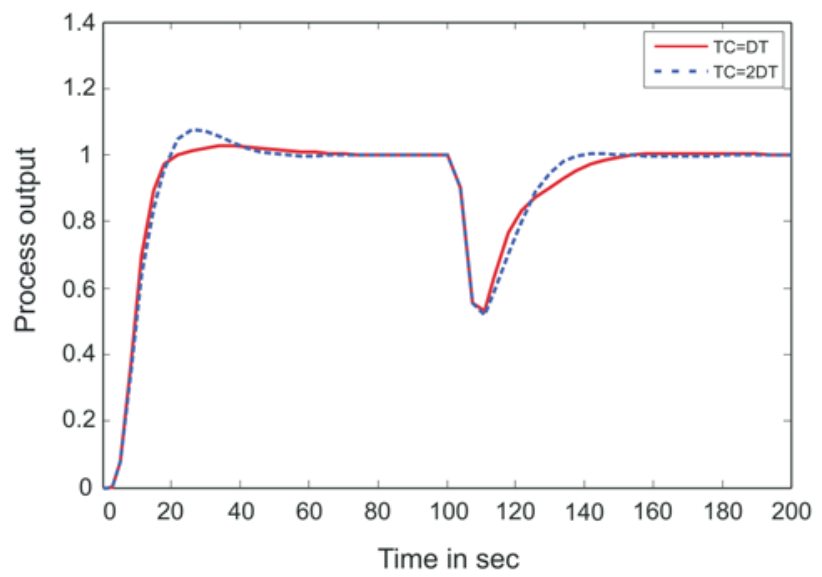

Figure 9: Time constant=2 times Dead time.

where

$$
\omega_{\mathrm{k}}=\frac{2 \pi_{\mathrm{k}}}{\mathrm{NT}_{\mathrm{s}}}
$$

$\mathrm{N}$ is the number of samples, $\mathrm{T}_{\mathrm{s}}$ is the sampling time, $G\left(j \omega_{k}\right)$ is the discretized frequency response of the actual system, and $G_{m}\left(j \omega_{k}\right)$ is the discretized frequency model

$$
\begin{aligned}
& G(j w k)=\frac{G_{p}(j w k) G_{i}(j w k)}{1+G_{p d}(j w k) G_{p}(j w k)} \\
& \varepsilon(j w k)=1-\frac{j w_{k}}{k_{i}} \frac{1+\left(K_{p}+j w_{k} k_{d}\right) G_{p}\left(j w_{k}\right) G_{m}\left(j w_{k}\right)}{G_{p}\left(j w_{k}\right)} \\
& =1-\phi\left(j \omega_{k}\right)^{T} \theta
\end{aligned}
$$

where $K_{i}, K_{p}, K_{d}$ are the integral, proportional and derivative gains, respectively.

$$
\begin{aligned}
& \phi\left(j w_{k}\right)=\left[1, G_{p}\left(j w_{k}\right), j w_{k} G_{p}\left(j w_{k}\right)\right] A\left(j w_{k}\right) \\
& \theta=\left[\frac{1}{K_{i}}, \frac{K_{p}}{K_{i}}, \frac{K_{D}}{K_{i}}\right]^{T} \\
& A\left(j w_{k}\right)=j w_{k} \frac{G_{m}\left(j w_{k}\right)}{G_{p}\left(j w_{k}\right)}
\end{aligned}
$$

Then the cost function $\mathrm{J}$ can be rewritten as

$$
\mathrm{J}=(\varphi-\phi \theta)^{\mathrm{T}}(\varphi-\phi \theta)
$$


where

$\phi=\left[\begin{array}{l}\phi\left(j \omega_{1}\right), \phi\left(j \omega_{2}\right) \ldots \ldots \ldots . . \phi\left(j \omega_{m}\right), \\ \phi\left(-j \omega_{1}\right) \phi\left(-j \omega_{2}\right) \ldots \ldots . . \phi\left(-j \omega_{m}\right)\end{array}\right]^{\mathrm{T}}$

$\varphi=[1,1, \ldots \ldots .1]^{\mathrm{T}}$

Using the least square algorithm, a real valued solution of $\theta$ that minimizes $\mathrm{J}$ is given by

$\theta=\left[\phi^{\mathrm{T}} \phi\right]^{-1} \phi^{\mathrm{T}} \varphi$

where $\mathrm{T}$ denotes the complex conjugate transpose.

\subsection{Simulation Results for Non-Self Regulating Processes}

The transfer functions considered is $G(s)=\frac{1}{s} e^{-3 s}$ and $\mathrm{G}_{0}(\mathrm{~s})=\frac{1 \mathrm{e}^{-3 \mathrm{~s}}}{\mathrm{~s}(1+3 \mathrm{~s})}$ for all the methods discussed above. The model is derived as per the above discussion in each method.

In the responses shown in Figure 10 it is clear that the alternate method proposed in this paper gives a fast response for both set point and load disturbance, with fast settling time.

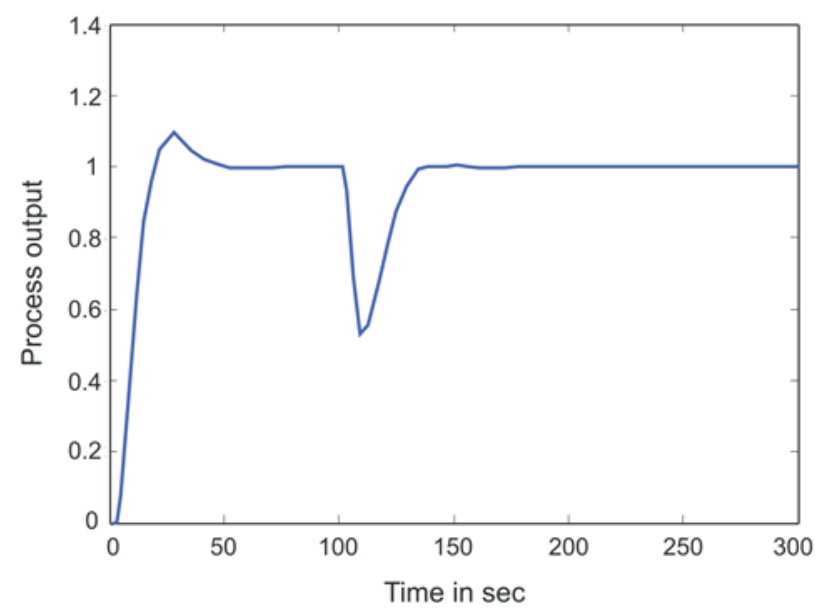

Figure 10: Set point and load response for a non-self regulating process by the proposed alternate method. ZN Tuning: $\mathrm{Kc}=0.22, \mathrm{Ki}=0.09, \mathrm{Ko}=0.04$
In Figure 11 the response of the proposed method acts as a compromise between both the set point and load disturbances by providing fast rise time and fast settling time with minimum overshoots and undershoots, whereas the other methods were able to produce only either a satisfactory set point response or a load response for disturbances. Hence, it is clearly proved that the proposed method has a good disturbance rejection property.

This method is also verified for the robustness of the controller with unmodeled dynamics (with changes in the dead-time).

In Figure 12 the set point response and load response of the system with a PID controller using the auto-tuning approach is shown. First, the response of analytical PID values is obtained by Ziegler-Nichols tuning. It is clear that the optimum tuning values give a good response with minimum overshoot and fast settling time. Next the adaptive PID values are obtained from the Matlab program, and those values too resulted in a compromise between minimum overshoot and fast settling time and the system is also under control. This was verified for both set point and load disturbances.

Thus, the I-PD controller discussed in the proposed method gives better response for both set point and load disturbances than the PI and PID controllers considered in the introductory part. Here the number of tuning parameters is only three, Kp, Ti and Td, which is also an added advantage of this method when compared to the previous modes of Smith predictors.

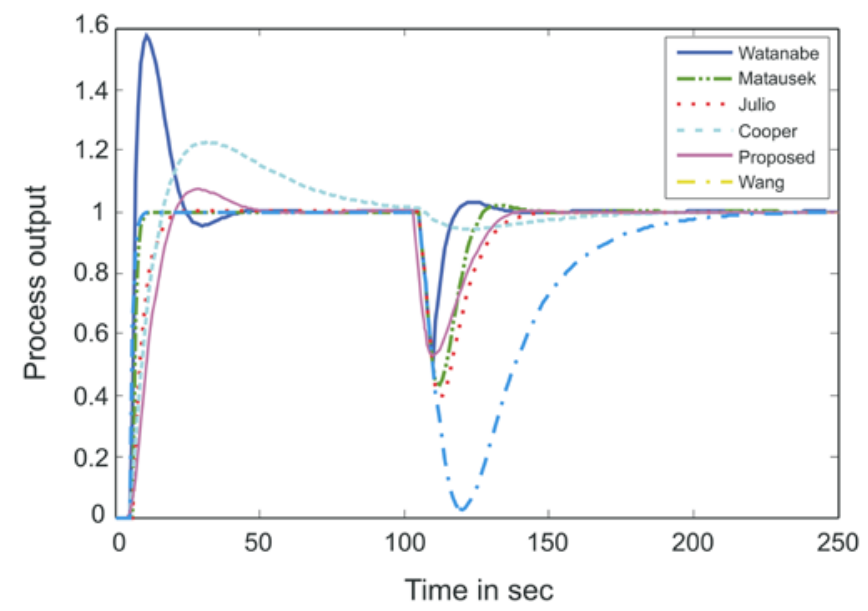

Figure 11: Set point and load responses of the proposed method in this paper for a non-self regulating process with other methods. 


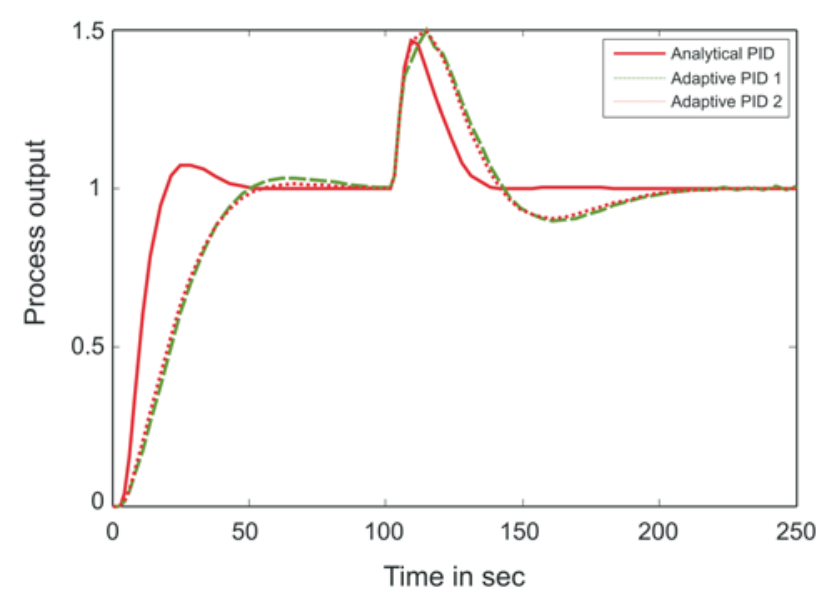

Figure 12: Set point response and load response of the system using IPD Controller with analytical and adaptive values using the auto-tuning approach.

\section{Robustness of the Proposed Method}

In this section the responses of the proposed method to changes in the set point for Benchmark process 1 are presented.

\section{a) Changes in the Set-Point Positive Mismatch Term}

For the benchmark 1 process with

$$
G(s)=\frac{1}{s} e^{-5 s}
$$

the negative mismatch term

$$
G(s)=\frac{0.8}{s} e^{-4.5 s}
$$

is introduced and observed for servo response of a unit step change at 0 sec. When compared with other modified Smith predictors, the proposed method gives minimum overshoot and fast settling time without oscillations, as shown in Figure 13.

\section{b) Changes in the Set-Point Positive Mismatch Term}

For the benchmark 1 process, the positive mismatch term

$\mathrm{G}(\mathrm{s})=\frac{1.2}{\mathrm{~s}} \mathrm{e}^{-5.2 \mathrm{~s}}$ is introduced and observed for servo response of an unit step change at 0 sec. When compared with other modified Smith predictors, the proposed method gives minimum overshoot and fast settling time without oscillations, as shown in Figure 14.

\section{c) Changes in the Load - Negative Mismatch Term}

For the benchmark 1 process the negative mismatch term

$$
G(s)=\frac{0.8}{s} e^{-4.5 s}
$$

is introduced and observed for load response of -0.1 unit at $100 \mathrm{sec}$. When compared with other modified Smith predictors, the proposed method gives minimum undershoot and fast settling time, as shown in Figure 15.

\section{d) Changes in the Load - Positive Mismatch Term}

For the benchmark 1 process, the positive mismatch term

$\mathrm{G}(\mathrm{s})=\frac{1.2}{\mathrm{~s}} \mathrm{e}^{-5.2 \mathrm{~s}}$

is introduced and observed for load response of -0.1 unit at $100 \mathrm{sec}$. When compared with other modified Smith predictors, the proposed method gives minimum undershoot and fast settling time, as shown in Figure 16. 


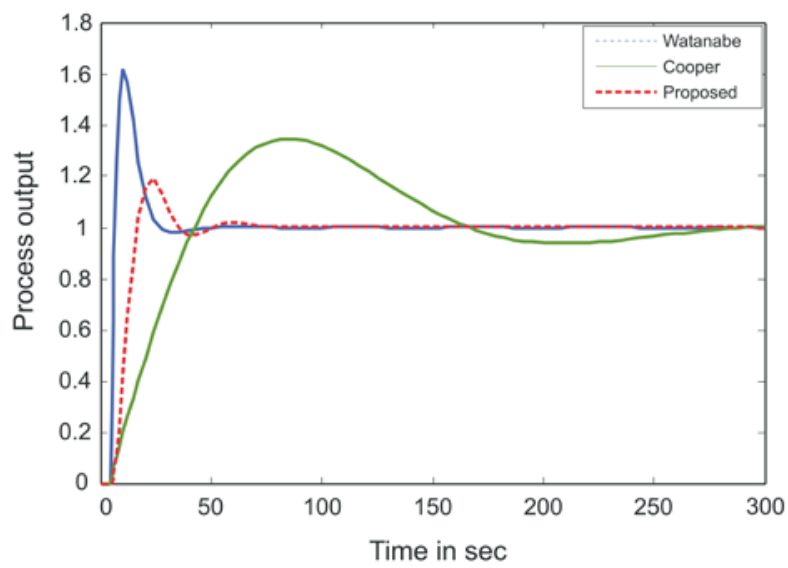

Figure 13: Servo response for negative mismatch term of BM processs 1

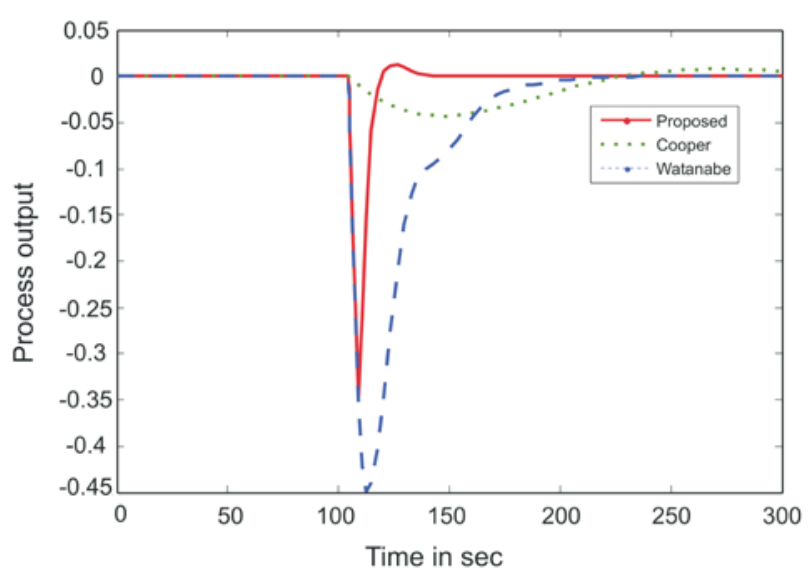

Figure 15: Load response for negative mismatch term of BM processs 1

\section{CONCLUSION}

An I-PD based modified DTC is designed for Integrator processes with long dead time. It gives a satisfactory response for both set point and load changes. A critically damped system that is as fast as possible is obtained by this method. It is also proved that there is no steady-state error for constant load disturbances. This method is also verified for the robustness of the controller with unmodeled dynamics. It is proved that the response of the process variable is good when the time constant of the model is equal to the dead time of the process. Thus, a critically damped system with fast set point response and load response is obtained.

\section{NOMENCLATURE}

G(s) Transfer function of the Plant

$\mathrm{G}_{0}(\mathrm{~s}) \quad$ Transfer function of the model

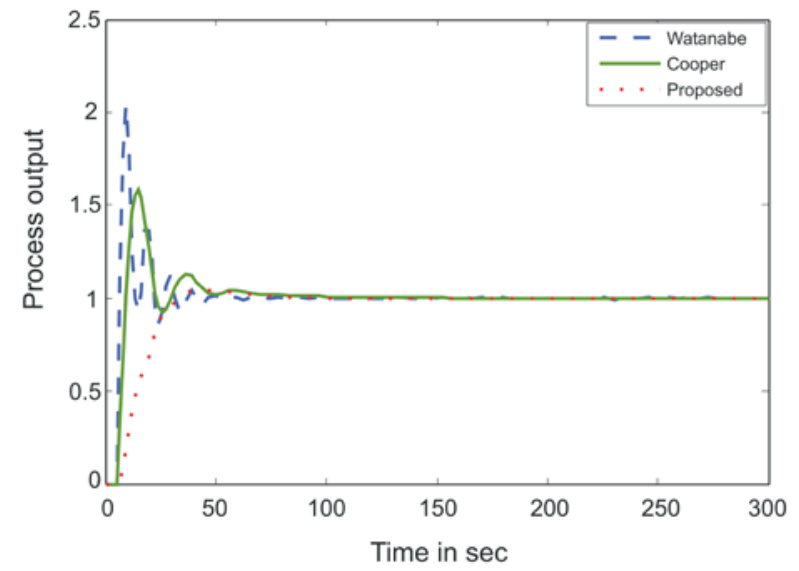

Figure 14: Servo response for positive mismatch term of BM processs 1

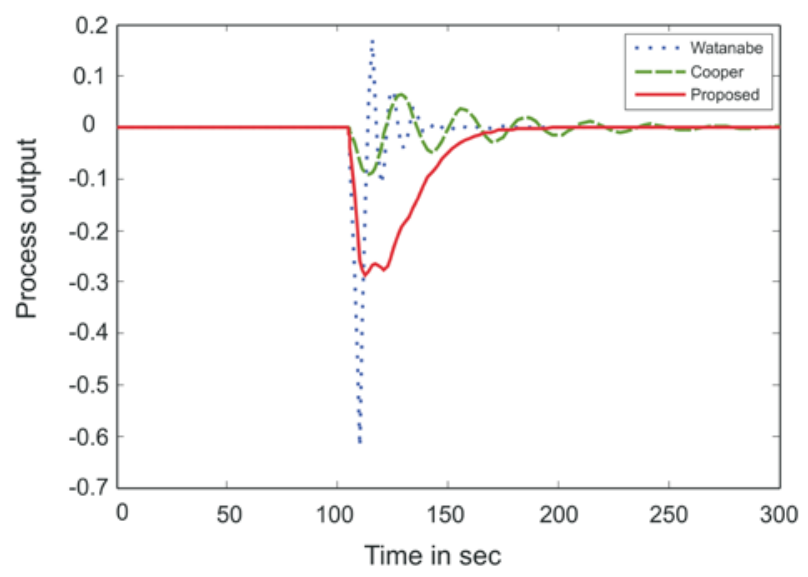

Figure 16: Load response for positive mismatch term of BM processs 1

$\mathrm{K}_{0} \quad$ Disturbance gain

$\mathrm{K}_{\mathrm{i}} \quad$ Integral gain

$\mathrm{K}_{\mathrm{d}} \quad$ Derivative gain

$\mathrm{K}_{\mathrm{p}} \quad$ Process gain

L Dead time

$\mathrm{T} \quad$ Time constant

$\mathrm{T}_{\mathrm{i}} \quad$ Integral time

$\mathrm{T}_{\mathrm{r}} \quad$ Related time constant of Controller gain $\mathrm{K}_{\mathrm{r}}$

$\mathrm{T}_{\mathrm{s}} \quad$ Sampling time

$\lambda \quad$ Model uncertainty

$\kappa \quad$ Normalized gain

$\theta \quad$ Adaptive controller gains

$\phi \quad$ Unit matrix

$\varepsilon \quad$ Error

\section{Acronyms}

DTC Dead time compensators

IMC Internal model controller

PID Proportional, Integral, 
Derivative

PIP Predictive Proportional Integral

GPM Gain phase margin

ZN Ziegler Nichols

FFT Fast Fourier transforms

I-PD Integral, proportional, Derivative

\section{REFERENCES}

Astrom K. J., Hang C. C. and Lim B.C., A new Smith predictor for controlling a process with an integrator and long dead-time IEEE Transactions on Automatic Control Vol 39, no. 2, p. 343- 345 (1994).

Coughanowr D. R., Process Systems Analysis and Control, McGraw-Hill International Edition, Chemical Engineering Series (1991).

Hagglund T., A predictive PI controller for processes with long dead-times IEEE Control Systems Magazine vol.12, no. 1, p. 57-60 (1992).

Matausek M. R. and Micic A. D., A modified Smith predictor for controlling a process with an integrator and long dead-time, IEEE Transactions on Automatic Control, vol. 41, No. 8, p. 1199-1203 (1996).

Normey-Rico J. E. and Camacho E. F., Robust tuning of DTC's for processes with Integrator and longer dead-time, IEEE Transactions on Automatic Control vol.44, no. 8, p.1597-1603 (1999).

Rice R. and Cooper D.J., Design and tuning of PID controllers for integrating (non-self regulating) processes, Procceding of the ISA Annual Meeting, Chicago (2002).

Santacesaria C. and Scattolini R., Easy tuning of Smith predictor in presence of delay uncertainty, Automatica, vol. 29, no. 6, p.1595-1597 (1993).

Saravanakumar G., Wahidabanu R. S. D. and Nayak C. G. , Design of modified Smith predictors for stable processes with integrator and longer deadtimes using adaptive control, International Journal on Automatic Control and System Engineering, vol 6, no. 4, p. 1-5 (2006).

Wang B., Rees D. and Zhong Q. C., Control of Integral process with dead-time Part IV: various issues about PI controllers, IEE Proc.-Control Theory and Applications, vol. 153, no. 3, p.302-306 (2006).

Watanabe K. and Ito M., A process-model control for linear systems with delay, IEEE Trans. Automatic Control., vol. 26, no. 6, p. 1261-1266 (1981).

Tyreus B. D and Luyben W. L., Tuning PI Controllers for Integrator Dead time processes, Ind. Eng. Chem. Res. vol. 31, p. 2625-2628 (1992).

Ziegler J. G. and Nichols N. B., Optimum Settings for Automatic Controllers, Trans. ASME, 64, p. 759-768 (1942). 